\title{
Wittgenstein on Logic as the Method of Philosophy: Re-examining the Roots and Development of Analytic Philosophy by Oskari Kuusela
}

\author{
Jakub Mácha
}

Kuusela, Oskari. Wittgenstein on Logic as the Method of Philosophy: Re-examining the Roots and Development of Analytic Philosophy. Oxford: Oxford University Press, 2019, xi +297 pp.

In this book, Oskari Kuusela his philosophical career. Kuusela maintains that for Wittgenstein, logic labels this particular conception of is the method of philosophy. This logic non-empiricist naturalism and claim would not be surprising if it contrasts it to apriorism, empiricism concerned Wittgenstein's early and conventionalism. A large portion thinking. Kuusela, however, insists of the book is devoted to developing that logic - properly understood - is this conception of logic, which, the method of philosophy even for roughly speaking, recognizes the the later Wittgenstein. The received relevance of the empirical facts of view is that the later Wittgenstein's contribution to logic (here is usually meant formal logic) is a negative one. But Kuusela identifies a positive role for logic and logical philosophy in Wittgenstein's later philosophy too. Moreover, he radicalizes this view by claiming that Wittgenstein remains a supporter of the Fregean-Russellian conception of philosophy throughout nature for logic. ${ }^{1}$

The subtitle, Re-examining the Roots and Development of Analytic Philosophy, promises to situate Wittgenstein's conception of logic within the broader context of analytic philosophy. And, indeed, Kuusela first focusses on Frege's and Russell's views of logic in order to establish what the so-called Fregean-Russellian conception of

\footnotetext{
${ }^{1}$ Kuusela is not alone in taking this approach to Wittgenstein's later philosophy. See, for example, Floyd (2016), Grève (2018).
} 
philosophy actually is. Wittgenstein's views are also contrasted with those of Carnap, whose approach is interpreted as a specific way of developing Wittgenstein's early philosophy of logic. The context into which Wittgenstein's philosophy is placed does not end with Carnap, however. The final part of the book situates Wittgenstein's later philosophy within the debate between ordinary language philosophy (represented by Strawson) and ideal language philosophy (as exemplified by Carnap). Contrary to the established view that Wittgenstein is a kind of ordinary language philosopher, Kuusela maintains that Wittgenstein's ideas are closer to Carnap's, and invoke ideal philosophical and logical models.

Before we look at particular chapters in closer detail, let me first make the general observation that the book is written in a very accessible style. The reader may almost forget about (or not even become aware of in the first place) the notorious interpretative debates surrounding Wittgenstein's work, and feel that this is a natural presentation of his philosophical ideas. This is due to the fact that the author presents his interpretation in the main body of the text, and (with a few exceptions) leaves clarifications of how it relates/contrasts to other interpretations for the endnotes. Understanding the main ideas of this book does nt presuppose any extensive familiarity with the vast secondary literature on Wittgenstein's philosophy - perhaps with the sole exception of Kuusela's earlier The
Struggle against Dogmatism (2008), many points from which are further developed in the reviewed book.

The first chapter focusses primarily on those of Frege's and Russell's views on logic that influenced Wittgenstein and that he advanced and developed in the Tractatus. These views are, first, that logic is the method of philosophy (for Russell, logic is the sole method; for Frege, it is one useful method). That is to say, philosophical problems can (or must) be approached and resolved by means of logical methods. Second, the goal of these methods is to develop a logically perspicuous language in the form of a symbolic notation, in order to move beyond the (potentially misleading) surface structures of natural languages and reveal the underlying logical forms. This is what Kuusela calls the Fregean-Russellian conception of philosophy. Wittgenstein, although critical of certain of Frege's and Russell's views, adopts this conception of logical philosophy in the Tractatus - with "a linguistic makeover", as Kuusela puts it (22). This is not particularly controversial. However, Kuusela also advances a more substantial claim: namely that Wittgenstein employed and developed this general philosophical outlook in his later work. Kuusela speaks in this connection of "a second revolution in logic, following Frege's and Russell's first revolution" (33).

In section 1.4, Kuusela makes an exception to his general maxim of not discussing other interpretations of Wittgenstein's philosophy in the main text, and relates his own reading to 
other contemporary interpretative approaches. In short, Kuusela proposes a kind of resolute reading ${ }^{2}$ of the Tractatus that is, however, not committed to viewing philosophy as therapy, i.e. not committed to ultimately giving up philosophical theorizing as nonsense. In contrast, the goal of Wittgenstein's logical philosophy is, on Kuusela's interpretation, to clarify our pretheoretical comprehension of logic. Logical insights cannot be expressed as necessary logical propositions; such principles can, however, be encoded in a logical language, in a perspicuous logical notation that logical philosophy seeks to develop. In support of this view, Kuusela brings up Wittgenstein's remark from 1929: "The notation is the last expression of a philosophical view." (Ms 105: 12; quoted on p. 44 in Kuusela's book)

In Chapter 2, Kuusela argues against established views that the Tractatus does not exclude the possibility of a meta-perspective. As is well known, Frege's and Russell's universalist conception of logic (i.e. a symbolism that has a fixed interpretation - in contrast to the contemporary model-theoretic conception of logic) usually implies the impossibility of a meta-perspective. However, as Kuusela stresses repeatedly, the task of logic (as a discipline) is to clarify what language users already know. The task of logic in the Tractatus is to remind language users of something that they may not fully understand. On this interpretation, logic is not a science, as Frege and Russell maintained; logical laws do not need to be a priori or even metaphysical truths. They can be conceived of as "the rules for the use of signs" (70).

Chapter 3 compares Wittgenstein's early philosophy with Carnap's approach. The goal of the Tractatus is restated in Carnapian terms: "to introduce, by means of only apparently metaphysical quasi-syntactical sentences, logical or syntactical principles and concepts that are constitutive of a logical language designed for the purpose of philosophical clarification in the formal mode" (77). This implies that Carnap's departure from Wittgenstein is less radical than Carnap himself thought. Both proposed a method for introducing logicosyntactical concepts. Kuusela maintains, contrary to Carnap (and contrary to the resolute reading of the Tractatus), that Wittgenstein's nonsense is clearly distinguishable from metaphysical non-sense by reference to its function, i.e. the introduction of syntactical concepts and principles. There are two main points of departure between Wittgenstein and Carnap. First, while Wittgenstein does not acknowledge the possibility of expressing logico-syntactical principles by means of propositions, Carnap does. Second, for Wittgenstein (as well as for Frege and Russell),

\footnotetext{
2 The expression "resolute reading" has become problematic. Many people, including Kuusela, use it for their own purposes. It is, however, clear that Kuusela wants to contrast his view to metaphysical and therapeutic interpretations of Wittgenstein's philosophy.
} 
representations of reality are the only type of sensible statements. This contradicts Carnap's principle of tolerance. For Carnap, logical and syntactical rules are conventional stipulations; for Wittgenstein, they are objects of discovery. Wittgenstein abandoned this view in his later philosophy.

The topic of the next three chapters is Wittgenstein's later philosophy. These chapters develop and ultimately lead to non-empiricist naturalism, as Kuusela calls the later Wittgenstein's conception of logic. In Chapter 4, Kuusela argues that Wittgenstein abandoned FregeanRussellian anti-psychologism by recognizing the relevance of empirical facts (of nature) for logic. He came to believe that in logic we compare language with calculi or games (with or without fixed rules). These idealized models serve as objects of comparison. Idealization thus serves a methodological purpose here (as it does in science). Actual logical models that may express idealizations of some kind (ideal simplicity, ideal exactness, etc.) do not suggest that these idealizations pertain to reality. However, the usefulness of these models (for the clarification of actual uses of language) depends on contingent facts about the way we use language and the environment we live in - even "the make-up of the human brain" (136), as Kuusela adds. Agreement in judgements is, after all, a contingent empirical fact. Note that some proponents of the resolute reading of the Tractatus argue that even the logical system introduced therein serves as an object of comparison (see Read/Deans 2011: 151), which Kuusela denies on exegetical grounds.

Chapter 5 examines the method of language-games, which is another method of clarification distinct from the calculus-based method discussed in the previous chapter. Languagegames are, like logical calculi, objects of comparison. As is well known, the (family resemblance) concept of a language-game is very flexible. Logical or formal calculi can be a kind of language-game. Wittgenstein thus advances a highly pluralistic conception of logic, which Kuusela argues goes beyond Carnap's principle of tolerance. Now, there are - or better yet, we can construct language-games with strict rules or without them. These rules can be formal or informal. A language-game can operate with formal or vague concepts. Even more importantly, a language-game can involve other yardsticks as objects of comparison. The emphasis of the method of language-games is not on rules, but rather on activities that grow out of forms of life. These models for clarification are usually simple and complete in themselves. Beyond their clarificatory function, they have a positive role in providing modes of representation (if these models/ language-games were only for clarification, there would not be any use for them after the philosophical problem was dissolved). Kuusela gives the following example of this: after the confusion underlying the postulation of private sensation-names has been cleared, Wittgenstein offers a positive 
role for such names, namely to serve as manifestations.

The book culminates in Chapter 6 , where non-empiricist naturalism is explained in detail. As this description suggests, naturalism as understood here is not a form of empiricism. Non-empirical naturalism is Wittgenstein's logical method. Logic, which on Kuusela's interpretation includes grammar, has arbitrary aspects (convention) and non-arbitrary aspects (dependence on facts of nature). It still holds that logic is a model of comparison that is not the source of (natural) necessity. How, then, can a logical/grammatical model depend on natural facts? Kuusela labels the employment of naturalistic methods in Wittgenstein's clarificatory endeavour "quasi-ethnology". It occurs in two main forms: either invoking a fictional natural history (e.g. fictional language learning or acquisition) or fictional tribes that use language in a particular way (e.g. "a primitive geometry of a tribe", a "system of communication of a tribe" or a tribe with "two systems of counting"). These ethnological models usually present primitive forms of languagegames (e.g. reporting sensations, asking for reasons, measuring). This should not be understood as the "ground-floor of a theory", but rather as "poles of a description" (195). Evidently, Wittgenstein cannot be taken to be committed to the claim that there are, for instance, people who have boxes containing beetles. The main point of this method is "to portray linguistic agents as embodied animals rather than as disembodied intelligences" (196). The rulefollowing discussion and the private language argument - arguably the central topics of the Philosophical Investigations - can be taken as examples of the quasi-ethnological method. Kuusela argues that this method "constitutes a radical transformation of Frege's, Russell's, and the Tractatus' philosophies of logic" (204). Wittgenstein might have been inspired here by Nietzsche's Genealogy of Morality, where stylized or even fictional histories of certain societies are also presented not in order to make empirical claims about them but rather to put emphasis on certain aspects of our moral behaviour. Under the heading "multidimensional logical descriptions", Kuusela further argues that such models can be employed in complementary or even simultaneous fashion (211) without contradiction. For example, there can be simultaneously employed yet different modes of representation; grammar can be arbitrary and nonarbitrary; meaning can be based on rules and sounds; mathematics can be pure and applied at the same time. This is, I think, a problematic point. We can, of course, employ more objects of comparison in order to clarify a philosophical confusion. However, employing them simultaneously can cause a further confusion, a "crossing of different language-games" (LWPP I: \$148), for one sentence can "fall "between several games"' (LWPP I: \$761). This worry is, I believe, central to the later Wittgenstein's thinking. One can wonder what exactly "simultaneously 
in a non-exclusive way" (2) actually means. If this means that one mode of representation does not exclude a later use of another mode of representation, then the worry can be avoided. If, in contrast, "simultaneous" means "within one language-game" or even that a certain expression can express different modes of representation, then the worry is potentially serious.

Let us move on to the seventh and final chapter, which situates Wittgenstein's philosophy, under the interpretation presented by Kuusela, within the debate between ideal and ordinary language approaches to philosophy, exemplified by Carnap and Strawson respectively. Wittgenstein and Strawson agree that philosophical problems have to be addressed by means of concepts originating in natural or ordinary languages. This, however, does not imply that we cannot use idealized models (as Wittgenstein and Carnap do) in order to clarify these philosophical problems. In the final section, Kuusela compares Carnap's method of explication with Wittgenstein's method of clarification. For Wittgenstein, employing logical models is temporary (we can always switch to another model), whereas Carnap's explication aims to establish a permanent link. One minor critical point: the debate between ordinary language philosophy and ideal language philosophy may seem to be outdated, although there are contemporary echoes of this debate. I mean, for example, the debate surrounding verbal disputes or the debate on logical pluralism. These more prominent debates could profit from (or be enriched by) Wittgenstein's conception of logic.

Kuusela's book deserves much praise for advancing a bold continuity thesis regarding Wittgenstein's philosophy and his conception of logic. If we accept Kuusela's interpretation emphasizing the role of logical notation in the Tractatus and objects of comparison in Wittgenstein's later philosophy, we can still ask how substantial this continuity is: can it really be right to count quasi-ethnology as a logical method? Kuusela argues, at the beginning of his book, that "on many occasions Wittgenstein uses the terms 'grammar' and 'logic' and their cognates interchangeably, and he never [...] seeks to explicitly distinguish grammar from logic" (6). Although Kuusela offers a great deal of evidence for this claim, the fact is that the later Wittgenstein preferred to use "grammar" rather than "logic". Kuusela's continuity thesis thus depends on stretching the term "logic" to include what Wittgenstein understands by the term "grammar". It holds, for Wittgenstein as well as for Kuusela, that "logic" cannot be equated with "formal logic" as many would do today. This is an instance of a more general issue: where is the word "logic" actually at home? Wittgenstein writes in PI: \$116:

When philosophers use a word - "knowledge", "being", "object", "I", "proposition/ sentence", "name" - and try to grasp the essence of the thing, one must always ask oneself: is the word ever actually used in 
this way in the language in which it is at home? -

What we do is to bring words back from their metaphysical to their everyday use.

I think we can add "logic" and "grammar" to this list of words philosophers use and try to grasp the essence of. Wittgenstein in the Tractatus, following Frege and Russell, used "logic" to capture the essence of logic and language. Does, however, Kuusela's book itself attempt to grasp the essence of logic? Of course it does not. There is an alternative interpretation: we can understand this extended concept of logic as a fictional one: "Nothing is more important though than the construction of fictional concepts, which will teach us at last to understand our own" (CV: 85). We can thus take Kuusela's redefinition of "logic" as an object of comparison that highlights a central trait of Wittgenstein's thinking. If so understood, Kuusela's book is a profound success.

Masaryk University, Czech Republic macha@mail.muni.cz

\section{References}

Floyd, J., 2016. "Chains of Life: Turing, Lebensform, and the Emergence of Wittgenstein's Later Style". Nordic Wittgenstein Review 5:2, 7-89.

Grève, S. S., 2018. "Logic and Philosophy of Logic in Wittgenstein". Australasian Journal of Pbilosophy 96:1, 168-182.

Read, R., and R. Deans, 2011, "The Possibility of a Resolutely Resolute Reading of the Tractatus". In M. Lavery and R. Read, eds., Beyond the Tractatus Wars: The New Wittgenstein Debate. London: Routledge, 149-170. 